\title{
Analysis of highway reflection noise reduction using transparent noise barrier types
}

\author{
Jaiyeop Lee ${ }^{1}$, Ilho $\mathrm{Kim}^{1,2^{+}}$, Seoil Chang ${ }^{3}$ \\ ${ }^{1}$ Environmental and Plant Engineering Institute, Korea Institute of Civil Engineering and Building Technology, Goyang 10223, Republic of Korea \\ ${ }^{2}$ Department of Construction Environment Engineering, University of Science and Technology, Daejeon 34113, Republic of Korea \\ ${ }^{3}$ Department of Environmental Engineering, University of Seoul, Seoul 02504, Republic of Korea.
}

\begin{abstract}
Transparent type noise barrier is a desirable facility since it provides a secure view to drivers and passengers. However, reflection from this type of barrier could annoy dwellers on the sides of the road. To reduce reflection noise by transparent type barrier, modification can be made to the shapes on the front side and hence get effects by distortion of sound transmission. To achieve this, we have conducted simulation by which the effects of patterned screens of noise barrier on high-ways were investigated. The reduction effects of reflected sounds were evaluated for swelling, swelling with curved, rectangular and V-shaped screen type barriers, compared to the planar panel. The emitting noise was generated by 6-lane road and the patterned noise barriers had shown the reduction effects, especially in swelling and swelling with curved type for middle height dwellers, and the V-shaped screen type for higher elevation dweller. The swelling-type showed a decrease of $0.7 \sim 1.2 \mathrm{~dB}$, performing the best diminution effect among the tested noise barriers.
\end{abstract}

Keywords: Curved-Type, Noise Barrier, Panel shape, Reflection noise, Sound Insulation Performance, Swelling-type

\section{Introduction}

Along with the rapid urbanization rate of Korea, various traffic pollutions took place within the last half-century. Especially, traffic noise damage by cars and trains has caused serious civil appeals and disputes. The environmental standards for noise in the Basic Environmental Law notes are stated to be $65 \sim 70$ and 55 60 Leq $\mathrm{dBA}$ in day (06:00 22:00) and night time (22:00 06:00), respectively. But, according to the Report on Conditions of Environmental Noise in Major cities of Korea, the noise exceeds over 7 10 Leq $\mathrm{dB}$, especially in overpopulated cities such as Seoul [1].

As effective plan to control undesirable noise from highway, there are several methods to apply, which fall under one or combination of source emission reduction, improving highway design and land use control mechanisms [2, 3]. The former two approaches face various potential troubles, such as alteration of circumstances in highway, design of vehicles and detailed understanding of noise generating conditions.

Noise barrier, on the other hand as an effective method to control the traffic noise, has been used for decades to reduce noise from highway which affected nearby residents [4]. This facility has been installed by predicting the propagation characteristics of traffic noise generated from the road. There are sound-absorbing noise, reflective noise and combined noise barrier types. In case of sound-absorbing noise barriers, the soundproof effect is extraordinary since sound-absorbing materials are used and these are usually installed in residential areas and highways in the downtown region $[5,6]$. The visual obstruction, however, exerts a negative image as materials such as aluminum and galvanized sheet iron are mainly used. Combined noise barriers do merge sound-absorbing and reflective noise barriers to simultaneously decrease the noise absorption and insulation, and are usually installed in vicinities that require partial visibility. A representative example of reflective noise barriers would be a transparent noise barrier, which are mostly used in places that require view, right of light and lighting. Because these noise barriers can optimize their unique transparency as much as possible to secure enjoying the scenery, the demand for their installation is particularly increasing.

There are a lot of studies made on the perception of noise barrier attenuation considering aesthetic to personal preference [7-9]. These studies reported that the constituent materials external design changes make people respond to attenuating noise. Such aesthetic design could make a role to reduce an upset about road
This is an Open Access article distributed under the terms of the Creative Commons Attribution Non-Commercial License (http://creativecommons. org/ licenses/by-nc/3.0/) which permits unrestricted non-commercial use, distribution, and reproduction in any medium, provided the original work is properly cited.
Received July 1, 2015 Accepted October 11, 2015

${ }^{\dagger}$ Corresponding author

Email: ihkim@kict.re.kr

Tel: +82-31-910-0649 Fax: +82-31-910-0291

Copyright (C) 2015 Korean Society of Environmental Engineers 
noise. But the residents dwelling near the highway perceive just noise in priority and not the visual effects.

Actually, the front design of noise barrier gives just not only aesthetic effects but also propagation of noise as sound power. Hayek has conducted analytical modeling on the transmission of noise reflecting from various shapes of noise barriers [10]. The mathematical theories offer a significant basis in calculating the noise that occurs in the field. He presented the propagation models of typical configurations, such as single, double and wedge wall, mainly based on Geometrical Theory of Diffraction (GTD).

On the rapid development of information technique, many models based on computing process about noise prospect have emerged. In 2001, Steele presented a critical review of the traffic noise prediction models on electric computing [11]. FHWA Traffic Noise Prediction Model, FHWA Traffic Noise Model, CoRTN, RLS90, MITHRA, STL-86 and ASJ-1993 were well compared in algorithm and propagation characteristics. Recently, Garg et al. followed former comparison works to come up with an update [12]. On their study, they considered newly developed models, such as HARMONOISE, Son Road model, NMPD-Routes-2008 and NORD2000. Among these four models, HARMONOISE and NORD2000 have the directivity which defines the directional head of sound source. In this study we have chosen NORD2000, since it offers abundant directivity index and frequency data; hence, adding various technical attributes which we face in various road conditions. Besides, NORD2000 makes possible to package the external built-in software, such as Virtual Lab and 3D CAD program, by which real-like circumstance can be prepared.

Meanwhile, materials such as Polycarbonate (PC), Polymethylmethacrlate (PMMA) and glass are used in transparent noise barriers. Based on their characteristics, since transparent noise barriers control noise by reflection, multiple noise damages can be caused to the opposite side. Despite the various strengths of transparent noise barriers, such as securing view, a weakness lies in the limited areas available for installation. However, there is a constant increase in requests to install transparent noise barriers that are absolutely advantageous in terms of view and lighting effects although the stated short comings are well known. In consequence, damages caused by noise reflected from the transparent noise barriers are likely to increase in the future, unless otherwise mechanisms to control the reflected noises are devised.

Saif et al. made a comparison of the cases in which single and parallel tilting noise barriers were set by varying the number of panels on the front [13]. Then, they found out the optimal setting condition for attenuation of noise. So by considering shapes and adjusting the designing factors of the front of noise barrier, it was possible to find the optimal factor for designing the facility. Even though the attenuation effects can be calculated, under complex field conditions, computation involving simulations will simplify things.

In this study, considering the various front designing factors, the optimal shape and condition were investigated using computing simulation. In our previous research work [1], we have demonstrated the effects of various shaped panels, such as wing, zigzag and curved form on reflected noise. From the simulation results of NORD2000, each shape showed significant effects on opposite site with optimized designing factors. This study also involves evaluation of the attenuation effects of reflection noise; however, by considering different types of screen noise barriers, instead of the soundproof panel shapes. Hence, the objective of the current study is to assess and come up with an alternative method to diminish the reflection noise.

\section{Materials and Methods}

\subsection{Noise Prediction Model}

In this research, Nord 2000, which has been applied to road traffic noise calculations since revised in 2005-2006, was employed [14-17]. The methodology adopted for the noise barrier prediction using Nord 2000 has been described in our previous work [1].

Nord 2000 gives a more sophisticated classification of mid-size cars and full-size cars of 2 axis, 3 or more than 4 axis compared to other similar noise prediction models, such as CRTN, RLS90, and NMPB. Besides, the octave analysis which offers 25 10,000 $\mathrm{Hz}$ with $1 / 3$ octave band is much wider than comparable models. Hence, Nord 2000 was selected as it provides relatively full information in noise prediction. The basic sound source model given by the following relation was used in this research.

$$
L_{E, 10_{m}}=L_{E}+10 \log \left[\frac{\sqrt{\left(d-\frac{w}{2}\right)^{2}+h_{r}^{2}}}{10}\right]-10 \log \left[\frac{\Delta \alpha}{2 \arctan (5)}\right]
$$

where: $L_{E, 10_{m}}=$ noise level at more than $10 \mathrm{~m}$ sway from noise source $[\mathrm{dB}]$

$d=$ measurement distance

$w=$ axle width of the venhicle

(if no $\infty$ or mation cars $=1.5 \mathrm{~m}$, trucks $=2.5 \mathrm{~m}$ )

$h_{r}=$ height of the microphone

$\Delta \alpha=\angle$ of ${ }^{\circ}$ ular sector coverint the / of integration[rad]

$$
\begin{gathered}
C(v)=L_{w}-L_{E, 10_{m}} \\
L_{w}=L_{E, 10_{m}}+C(50)+10 \log \left(\frac{v}{50}\right)
\end{gathered}
$$

To calculate the noise level, Nord 2000 applies the data measured where the distance between the road and the receiving point ranges from $7.5 \mathrm{~m} \sim 15 \mathrm{~m}$ and the height is $0.2 \mathrm{~m}$ and $4 \mathrm{~m}$ above the ground level to refer the input set value of noise level such as $L_{e, 10_{m}}$. Eq. (1) is used for noise levels at points where more than $10 \mathrm{~m}$ is apart from the middle of the road. The directivity and revised distance attenuation $(C(v))$ is calculated as in Eq. (2) and Eq. (3) indicates how to calculate $L_{w}$ (sound power levels by frequency) according to the change of car speeds, by using Eq. (1) and (2). The standard speed is 50 $\mathrm{km} / \mathrm{h}$ and the value of $C(50)$ transforms the measurements at $10 \mathrm{~m}$ of distance and heights of $0.2 \mathrm{~m}$ and $4 \mathrm{~m}$ from the receiving point into a database. 


\subsection{Setting up the Conditions of Noise Prediction}

Here, the type of vehicles that generate noise pollution are categorized into mid-size cars (Category 1), full-size cars with 2 axis (Category 2) and full-size cars with more than 4 axis (Category 3). Table 1 presents the computation conditions of each sound power levels which has been calculated as the hourly average noise level. Based on the number of axis, width of wheels, and distance between left and right wheels, Ministry of Land, Infrastructure and Transport of Korea categorized Vehicles into 12 types, whereas the Korea Expressway Corporation re-categorizes the 12 types into 5 and determines each noise level. Nord 2000 uses a combination of the number of axis and the weight, unlike the domestic standards, which consider the number of axis in the vehicle.

On the other hand, Table 2 and Table 3 show how representative sound directivity models such as Nord 2000 calculate the directivity. Directivity noise sources are those noises which are based on an identical sound source, however different sizes of reflection noise by directions. Sound directivity models have been developed through foreign standard models and individual research projects. Members of the EU especially possess customized models for their domestic conditions through long-term research.

Heights of noise sources (Source 1, 2, 3) that appear in Table 2 and Table 3 refer to the heights of noise sources that are emitted from the road, often used in mathematical models. Although they vary according to the vehicle categorization and the types of models

Table 1. Computation Conditions of Sound Power Level

\begin{tabular}{lcc}
\hline & Vehicle number (cars/h) & Vehicle \\
\hline Category 1 & 1000 & 100 \\
Category 2 & 20 & 100 \\
Category 3 & 10 & 100 \\
\hline
\end{tabular}

Table 2. Horizontal Directivity of Mid and Full-Size Cars (Nord 2000)

\begin{tabular}{lccc}
\hline & $\begin{array}{c}\text { Height } \\
\text { (m) }\end{array}$ & $\begin{array}{c}\text { Frequency range } \\
\text { (Hz) }\end{array}$ & Directivity \\
\hline Source 1 & 0.01 & $1,600-10,000$ & $-5+7 \mathrm{abs}(\cos (\varphi))$ \\
Source 2 & 0.15 & $1,600-10,000$ & $-5+7 \mathrm{abs}(\cos (\varphi))$ \\
Source 3 & 0.30 & $1,600-10,000$ & $-5+7 \mathrm{abs}(\cos (\varphi))$ \\
\hline
\end{tabular}

employed, the lowest sound source means the friction noise between tires and the road surface and the mid-height sound source means engine noise in case of small cars whereas it means exhaustion noise for full-size cars. The highest sound source, on the other hand, would mean engine noise for small cars and exhaustion noise for full-size cars. These are not absolute in any terms and can differ from models to models.

The directivity of Nord 2000 cannot calculate the vertical directivity and since it is in conflict in terms of the height of noise sources, with SoundPlan 7.2, the prediction program used in this study, the directivity in this research has been calculated based on the Harmonize model.

According to the vehicle categorization provided in Table 1, the noise levels for each frequency based on the heights of sound source (directivity heights of the Harmonize model) have been calculated for the simulation and Table 4 shows the results. Noise level has also been calculated via SoundPlan 7.2, a noise prediction program. Each simulation has been based on the ray-tracing method.

\subsection{Conditions for Predictions of Noise Level by Lanes}

Fig. 1 shows a prediction of noise delivery distribution when a noise level of $63 \mathrm{~Hz}$ is emitted from each lane towards a $5 \mathrm{~m}$ tall flat-type noise barrier. From items (c) to (f) of the figure, it has been forecasted that the noise emitted from the 1st lane on the barrier side and the opposite side have not been much influenced by the noise barrier. This is probably because, the noise barrier is quite far from the source that the reflection noise is almost undetectable, i.e., it is attenuated by the distance. Moreover, as Fig. 1 (a) depicts, it has been predicted that the influence of noise barriers will be exaggerated when noise occurs from the 3rd lane on the noise barrier side. A possible reason might be that when the distance between the noise source and the noise barrier is too close, it will be almost similar to a case of direct noise.

The conditions for the simulation will be most similar to the reality when the prediction is based on all the lanes, making the 6 -lane road the standard. But when conducting the simulation prediction, we have selected the 2nd lane on the noise barrier side as the basic condition for noise prediction, to best depict the prediction results.

Table 3. Automobile Directivity Model of Harmonize

\begin{tabular}{lccc} 
& Height $(\mathbf{m})$ & Frequency range (Hz) & Directivity \\
\hline Source 1 & 0.01 & $\mathrm{f} \leq 1250 \mathrm{~Hz}, \mathrm{f} \geq 8000$ & 0 \\
Source 2 & 0.30 & $1,600 \mathrm{~Hz} \leq \mathrm{f} \leq 6,300$ & $-1.5+2.5 a b s(\cos (\varnothing)) \sqrt{(\cos (\Psi)}$ \\
Source 3 & 0.75 & - & 0 \\
\hline
\end{tabular}

Table 4. Calculated Sound Power Level (dB)

\begin{tabular}{ccccccccccc}
\hline & Height (m) & $\mathbf{6 3} \mathbf{~ H z}$ & $\mathbf{1 2 5} \mathbf{~ H z}$ & $\mathbf{2 5 0} \mathbf{~ H z}$ & $\mathbf{5 0 0} \mathbf{~ H z}$ & $\mathbf{1 0 0 0} \mathbf{~ H z}$ & $\mathbf{2 0 0 0} \mathbf{~ H z}$ & $\mathbf{4 0 0 0} \mathbf{~ H z}$ & $\mathbf{8 0 0 0} \mathbf{~ H z}$ & $\mathbf{O v e r a l l}$ \\
\hline S1 & 0.01 & 77.39 & 77.49 & 77.69 & 78.59 & 82.99 & 80.29 & 80.19 & 81.79 & 89.05 \\
S2 & 0.3 & 70.23 & 70.33 & 70.53 & 71.43 & 75.83 & 73.13 & 73.03 & 74.63 & 81.89 \\
S3 & 0.75 & 73.14 & 73.24 & 73.44 & 74.34 & 78.74 & 76.04 & 75.94 & 77.54 & 84.8 \\
\hline
\end{tabular}



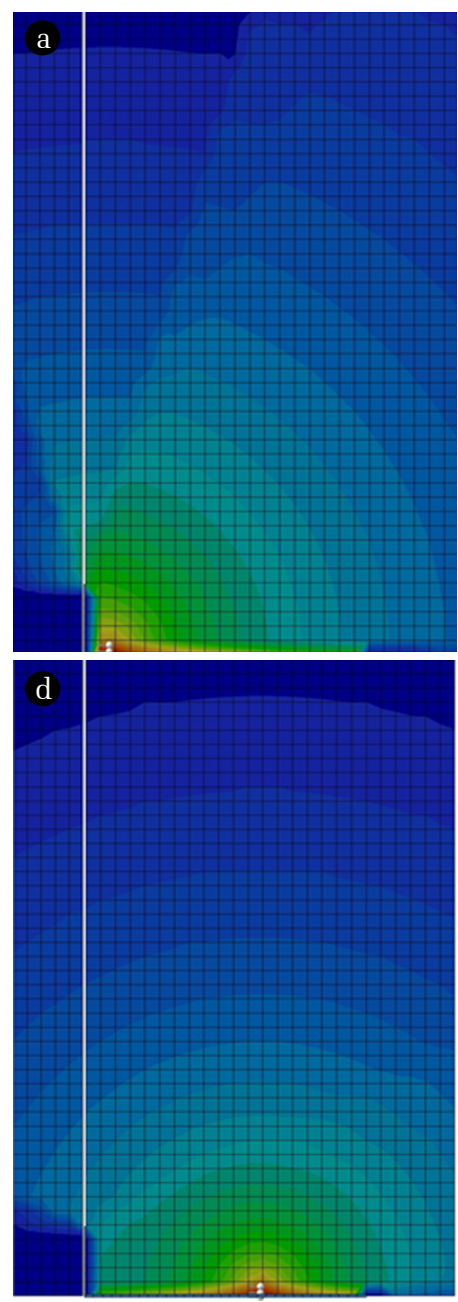
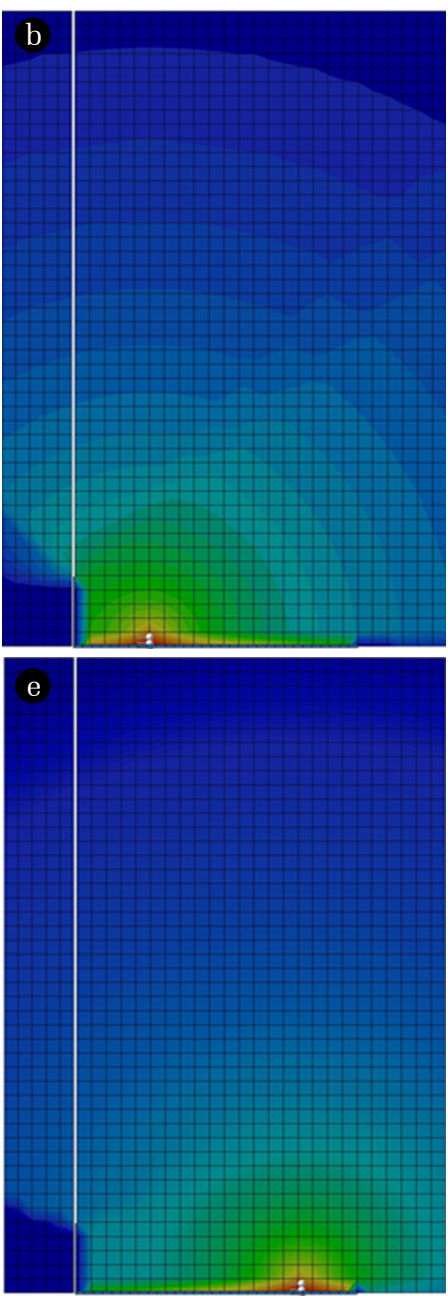
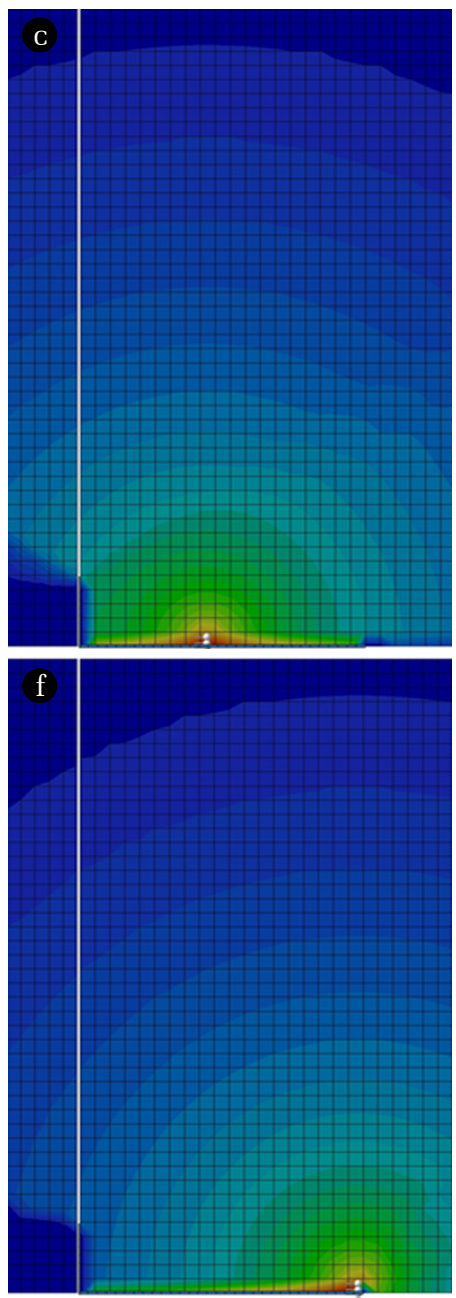

Fig. 1. Delivery of noise from noise barriers by lanes $(63 \mathrm{~Hz}$ ). (a) First lane on the noise barrier side; (b) Second lane on the noise barrier side; (c) Third lane on the noise barrier side; (d) First lane on the opposite side; (e) Second lane on the opposite side; (f) third lane on the opposite side.

\subsection{Research Subject: Forms of Noise Barriers}

This research aims to review the reduction effects of the reflection noise according to the shapes of the barriers. To this end, the study will follow the format of a comparative analysis on the reflection noise between the existing flat-type noise barrier and swelling-type (Fig. 2(a)), swelling + curved-type (Fig. 2(b)), and screen-type (Fig. 2(c)) noise barriers.

The design factors for each form will include: first, for the swelling-type noise barrier, the depth of the swelling (a); secondly for swelling + curved forms, the width of the curve (a) and height of the curved peak (b) and; last but not least, for screen types, the shape of the screen (rectangular and triangular (V-shape)) in order to evaluate the diminution effects of the reflection noise according to the values of each design factor. Also, the reflection noise is measured by frequency, ranging from $65 \mathrm{~Hz}, 125 \mathrm{~Hz}$, $250 \mathrm{~Hz}, 500 \mathrm{~Hz}, 1,000 \mathrm{~Hz}, 2,000 \mathrm{~Hz}$, and 4,000 Hz to 8,000 Hz.

In case of common residential housings, because noise levels are normally measured in a unit of 5 floors, we conducted the experiments of measuring the reflection noise at $15 \mathrm{~m}$ (R1), a usual height for a 5-story building and at $30 \mathrm{~m}$ (R2) that is level with usual $10^{\text {th }}$ floors on the opposite side of the noise barrier. Additionally, to check whether the noise level increases at the inside of the road (R3) compared to the flat-type noise barrier, the noise level was measured at $2 \mathrm{~m}$ above the middle of the road (Fig. 3).

The points of receiver are decided as follows. Ordinarily, noise is assessed at every 5 stories for analysis of environmental case in Korea. So, $15 \mathrm{~m}$ and $30 \mathrm{~m}$ were set to receiver points for middle and high point for residents, respectively. And in Enforcement Decree or the architecture law in Korea, it is set that the residences were located $6 \mathrm{~m}$ from the end of the road. Besides, in the standard notice of Ministry of Environment, the receiver should be placed $1 \mathrm{~m}$ by side from the noise barrier. So the distance of receiver of this study was set to be $5 \mathrm{~m}$ from the end of road (R1, R2). Adding to this, to assess the generated noise in the middle of the road, R3 as a receiver was set as Fig. 3. 

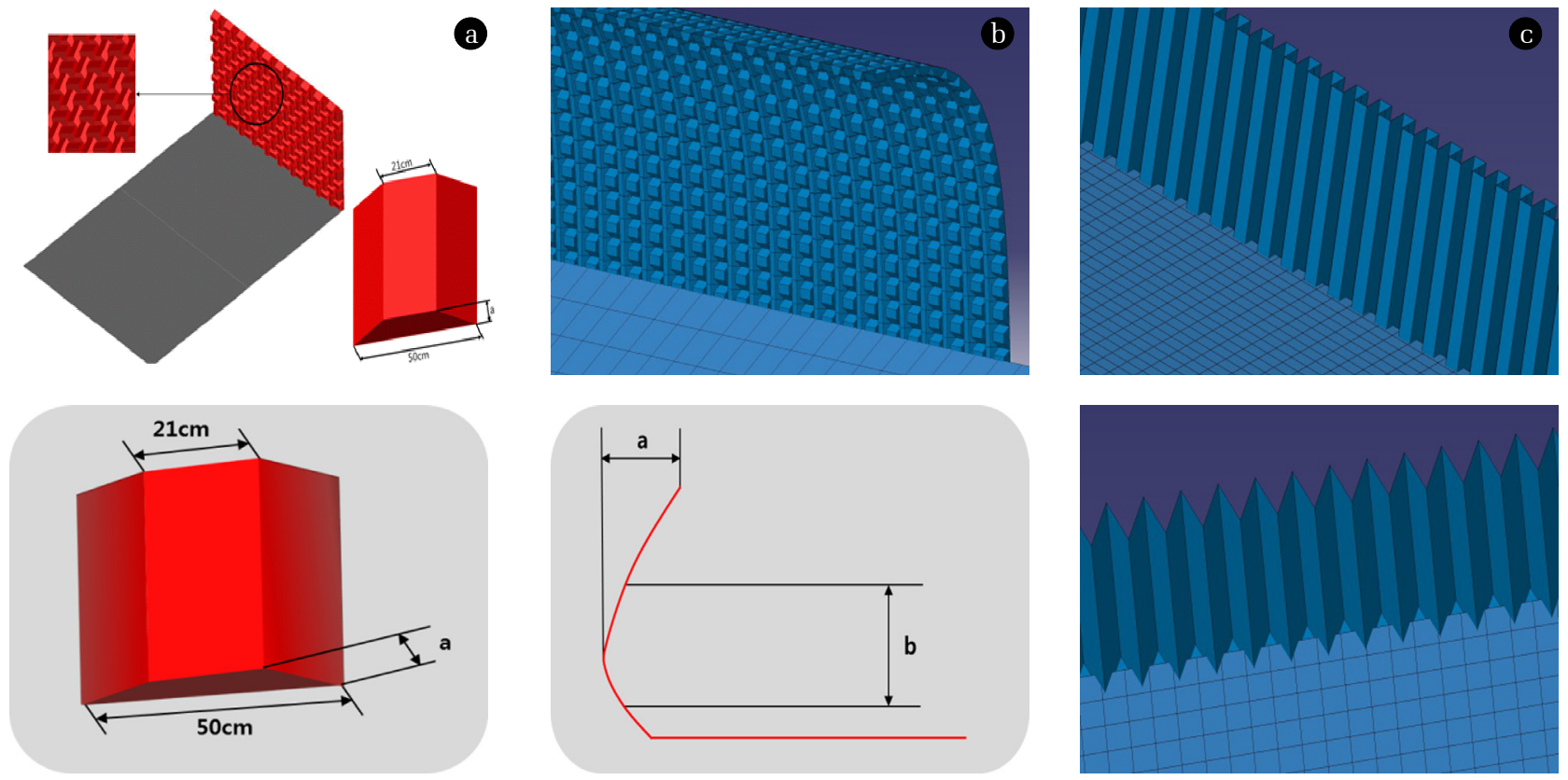

Fig. 2. Design factors and forms of the noise barrier. (a) Swelling type; (b) swelling + curved type; (c) screen type.

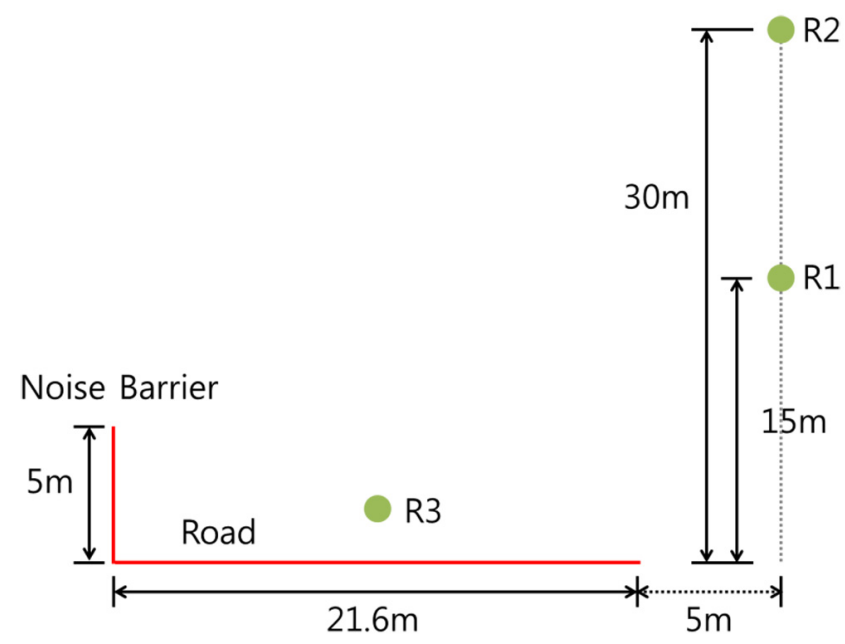

Fig. 3. Location map of comparison point about noise level.

Table 5. Predictions of Reflection Noise from Flat-Type Noise Barriers

\begin{tabular}{lc}
\multicolumn{1}{c}{ Prediction measuring point } & Predicted noise level (dB) \\
R1 $(15 \mathrm{~m})$ & 59.7 \\
R2 $(30 \mathrm{~m})$ & 55.6 \\
R3 (Middle of the road, $2 \mathrm{~m})$ & 71.1 \\
\hline
\end{tabular}

\section{Results and Discussion}

\subsection{Diminution Effects of Reflection Noise on Flat-type Noise Barriers}

To evaluate the diminution effects of reflection noise by shapes of the noise barriers, we first reviewed that of the flat-type noise barriers which are being widely used nowadays. The diminution effect has been calculated by frequency, as shown in Fig. 4. As shown in the figure, although the diffusion direction of the reflection noise slightly differs from one frequency to another, the values mostly tend to diffuse towards the diagonally opposite direction from the noise barrier. Also, we can see that the distribution of the left and right sound rays follow an uneven pattern from the borders of the diffusion direction of the reflection noise.

Table 5 describes a prediction of noise levels at points R1, R2 and R3. First, the predicted reflection noise at R1 - $15 \mathrm{~m}$ high and opposite from the noise barrier - was $59.7 \mathrm{~dB}$. At R2, a point $15 \mathrm{~m}$ higher than $\mathrm{R} 1$, the prediction value decreased by $4 \mathrm{~dB}$ to score $55.6 \mathrm{~dB}$. On the other hands, at R3 $-2 \mathrm{~m}$ above the middle of the road and the closest to the noise source - it was predicted to reach $71.1 \mathrm{~dB}$.

\subsection{Diminution Effects of Reflection Noise on Swelling-Type Noise Barriers}

The experiment conditions and results for the swelling-type noise barriers are shown in Table 6. To go over the results, in cases of B-2 and B-3 where the depth of swelling (a) were 20 and $30 \mathrm{~cm}$, the predicted noise level at R1 were 58.6 and $58.5 \mathrm{~dB}$, showing a decrease of $1.1 \sim 1.2 \mathrm{~dB}$ in reflection noise. But at $\mathrm{R} 2$ and R3, the reflection noise either increased or remained the same. With B-1 where the value of $10 \mathrm{~cm}$, the noise level was predicted as $59 \mathrm{~dB}$ at $\mathrm{R} 1$, showing a $0.7 \mathrm{~dB}$ diminution effect. But at R2 and R3, unlike B-2 and B-3, the measures were identical at R2 and decreased $0.1 \mathrm{~dB}$ at R3. Fig. 5 provides an understanding of the noise variation compared to flat-type noise barriers. Because the effects at R3 were insignificant, their values were omitted. 

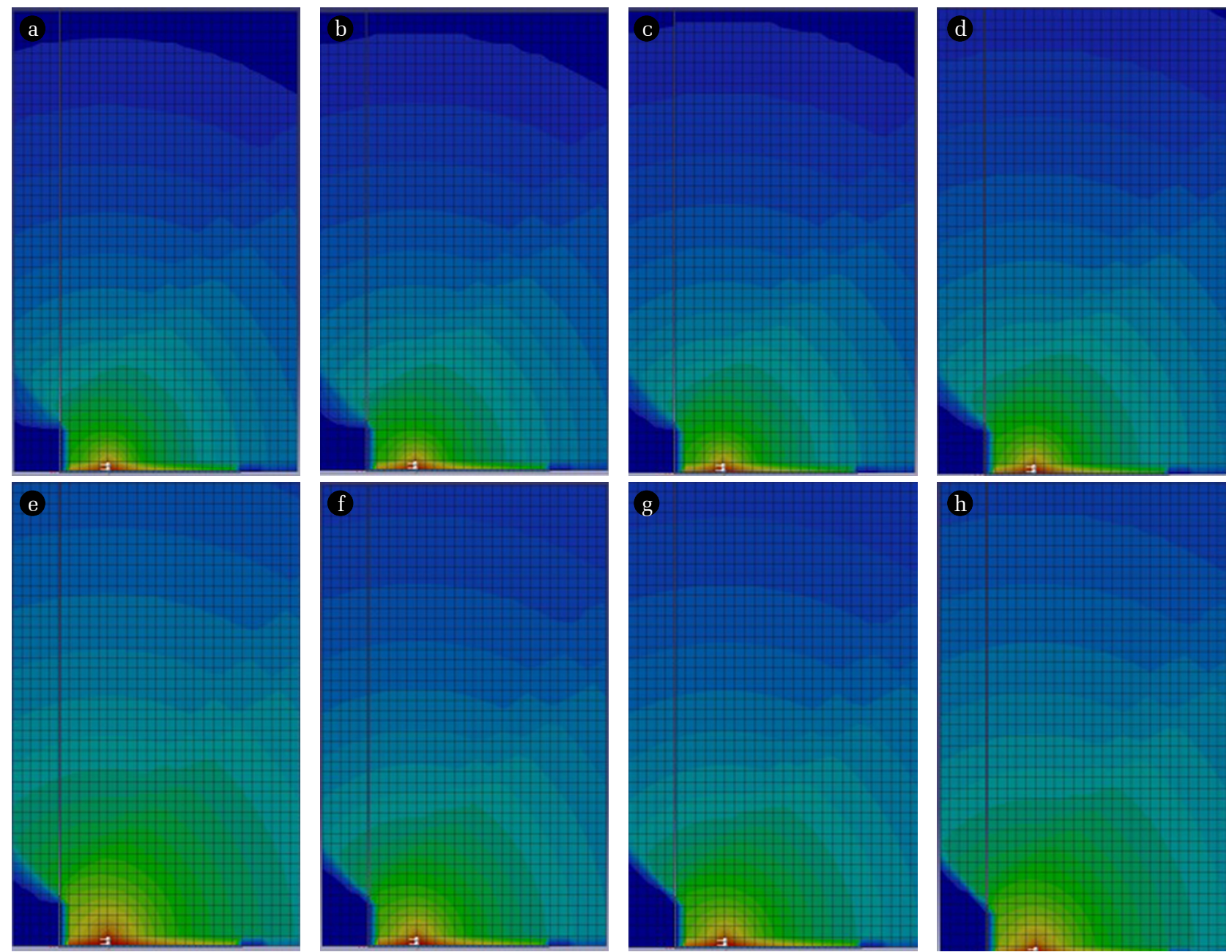

Fig. 4. Diffusion of reflection noise from flat-type noise barriers by frequency. (a) $65 \mathrm{~Hz}$; (b) $125 \mathrm{~Hz}$; (c) $250 \mathrm{~Hz}$; (d) $500 \mathrm{~Hz}$; (e) 1,000 Hz; (f) 2,000 Hz; (g) 4,000 Hz; (h) 8,000 Hz.

Table 6. Predictions of Reflection Noise from Swelling-Type Noise Barriers (attenuation/increment to plane)

\begin{tabular}{cccccc}
\hline \multicolumn{3}{c}{ Measuring Conditions } & \multicolumn{3}{c}{ Noise level from each receiving point (dB) } \\
\hline Models & Depth of the swelling (a) & & R1 (15 $\mathbf{~ m})$ & R2 (30 m) & R3 (middle of the road) \\
\hline B-1 & $10 \mathrm{~cm}$ & -0.7 & 0.0 & -0.1 \\
B-2 & $20 \mathrm{~cm}$ & -1.1 & +0.3 & 0.0 \\
B-3 & $30 \mathrm{~cm}$ & -1.2 & +0.5 & 0.2 \\
\hline
\end{tabular}

Taking into account its special forms, it was expected that swelling-type noise barriers would display a high diminution effect of reflection noise than flat-type noise barriers. Because swelling-type noise barriers symbolize the swellings of an anechoic chamber, we have expected the sound source to hit the swellings on the inside parts of the noise barrier; however, the prediction results showed a different finding. Actually, the predictions illustrated that although the reflection noise decreased at R1, it was increased at R2. Therefore, swelling-type noise barriers can be installed only in regions with low-level buildings and facilities.

\subsection{Diminution Effects of Reflection Noise on Swelling + Curved-Type Noise Barriers}

Swelling + curved-type noise barriers are a noise barrier type that combined a curved panel on the swelling-type noise barriers discussed under 3.2. Table 7 summarizes the measuring conditions and results of the present type. At R1 and R3, the predictions were 59.1 and $70.8 \mathrm{~dB}$, showing a diminution effect of reflection noise of 0.6 and $0.3 \mathrm{~dB}$, compared to flat-type noise barriers. Fig. 5 shows the noise variation in comparison with flat-type noise barriers and a slight increase was detected at R2. 
Effects on Noise by Swelling type with Curved Panel Comparing to Flat type

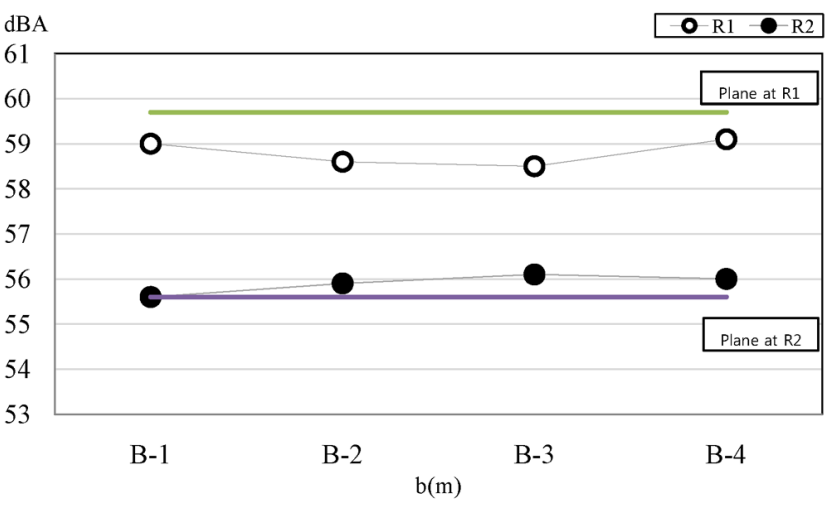

Fig. 5. Amount of noise reduction of swelling-type and swelling + curve-type noise barriers compared to flat-type.

The curves on the noise barriers induced a screening effect to diminish the noise that was delivered to the very top of the barrier and the swellings reflected the noise delivered to the side, off to the inside due to scattering effect, thus leading us to expect a diminution effect of reflection noise. But the actual results suggested that at R1 and R3, although the reflection noise was predicted to decrease, it increased at R2. Therefore, swelling + curved-type noise barriers also can be installed only in regions with low-level buildings and facilities.

\subsection{Diminution Effects of Reflection Noise on Screen-Type Noise Barriers}

The experiment summary for screen-type noise barriers is shown in Table 8. With rectangular screen-type noise barriers, we have varied the measuring points as shown in Fig. 6 to predict the noise variation according to each point source, because when setting up the sound source during the simulation process, it appeared as a group of point sources for every unit distance $(1 \mathrm{~m})$. For Rec-1, we placed the measuring points on the borders of the asperity and embedded areas as Fig. 6(a) and for Rec-2, on the center of the embedded area as in Fig. 6(b).

The prediction results suggested that the noise levels at R1 and R3 in every conditions would lead to higher or similar level of reflection noise. R2 in case of rectangular noise barriers also displayed increased measurements of reflection noise in all conditions. For V-1 cases, the predicted noise level at R2 is 55.1 $\mathrm{dB}$, a $0.5 \mathrm{~dB}$ decrease than flat-type barriers. At R1 and R3, 60.2 and $71.6 \mathrm{~dB}$, respectively, were predicted, showing an increase of $0.5 \mathrm{~dB}$. Fig. 7 shows the noise variation of screen-type noise barriers compared to flat-type barriers. Being insignificant at R3, their values were also omitted. Here, we can see that the diminution effects of reflection noise for screen-type noise barriers are either less powerful or even negative.

Considering the form of screen-type noise barriers, we have

Table 7. Predictions of Noise Level of Swelling + Curved-Type Noise Barriers (attenuation/increment to plane)

\begin{tabular}{|c|c|c|c|c|c|c|}
\hline \multicolumn{4}{|c|}{ Measuring conditions } & \multicolumn{3}{|c|}{ Noise level from each receiving point (dB) } \\
\hline Model & a (m) & b (m) & Depth of swelling (cm) & R1 (15m) & R2 (30m) & R3 (middle of the road) \\
\hline B-4 & 1 & 4 & 10 & -0.6 & +0.4 & -0.3 \\
\hline
\end{tabular}

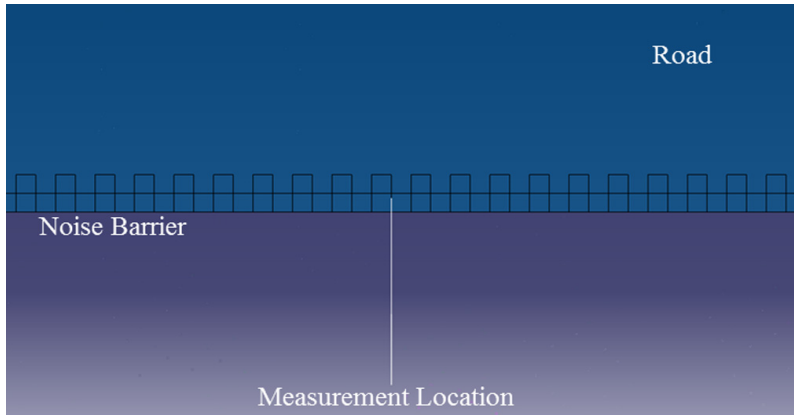

Rec-1

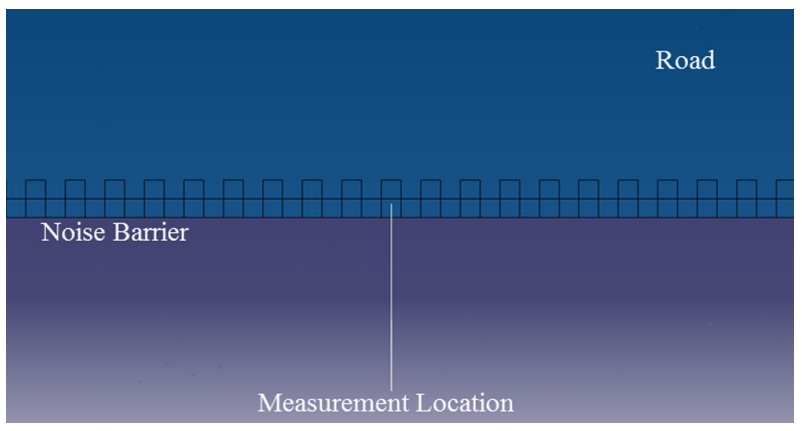

Rec-3

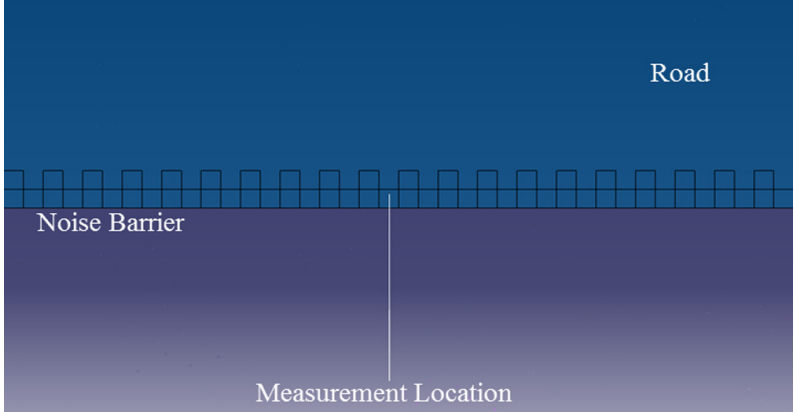

Rec-2

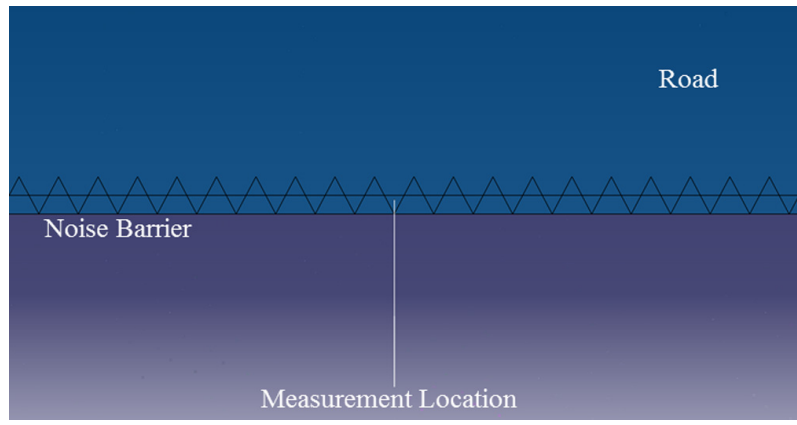

V-1

Fig. 6. Predicted position of screen-type noise barriers. 
Table 8. Predictions of Noise Level of Screen-Type Noise Barriers (attenuation/increment to plane)

\begin{tabular}{cccccr}
\hline & Measuring conditions & & Noise level from each receiving point (dB) \\
\cline { 1 - 4 } Model & Characteristics of screen & R1 (15 $\mathbf{~ m})$ & R2 (30 $\mathbf{~ m})$ & R3 (middle of the road) \\
\hline Rec-1 & Rectangular - borders & & +0.1 & +0.6 & +0.2 \\
Rec-2 & Rectangular - embedded & +0.1 & +1.1 & +0.3 \\
Rec-3 & Rectangular - asperity & 0.0 & 0.0 & 0.0 \\
V-1 & Triangular (V-shape) & +0.5 & -0.5 & +0.5 \\
\hline
\end{tabular}

Effects on Noise by four Screen type Comparing to Flat type

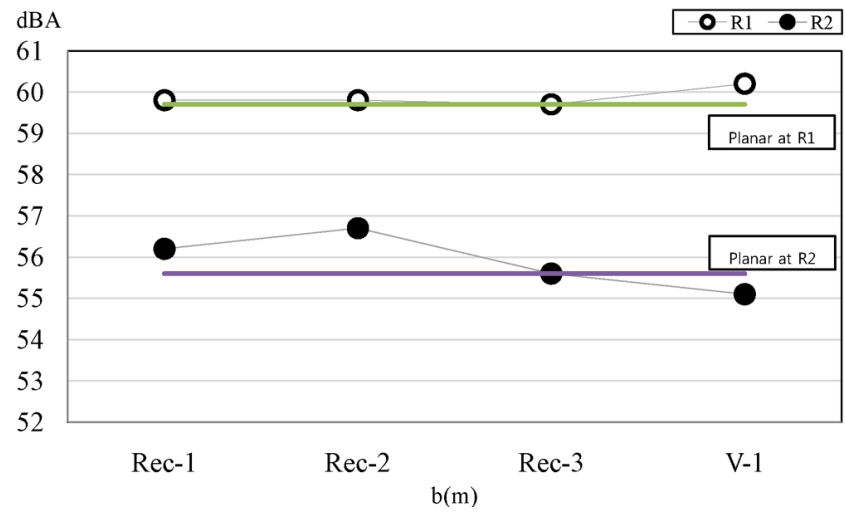

Fig. 7. Amount of noise variation of swelling + curved-type noise barriers compared to flat-type.

expected that the inside of the screen on the barriers will reflect the noise to display a higher level of diminution effect than flat-type barriers. Especially the measurements at the asperity parts of the rectangular and the triangular noise barriers increased the reflection noise, thus leading us to conclude that the applicability of screen-type noise barriers is lower than other types of barriers (Table 8).

\section{Conclusions}

This study predicted and analyzed the diminution effects of reflection noise of transparent noise barriers by considering forms of swelling-type, swelling + curved-type and screen-type barriers, compared to normal flat-type panels. By designing the noise barriers by shape and running the prediction program by inserting the noise source on the $2^{\text {nd }}$ lane to the noise barrier side among the 6 lanes, the reflection noise slightly decreased or increased in all noise barriers. At R1, especially in the cases of the screen-type noise barriers, it was predicted that no diminution effect were to occur in all conditions. However, the swelling-type showed a decrease of $0.7 \sim 1.2 \mathrm{~dB}$ at R1, performing the best diminution effect among the tested noise barriers. Compared to other forms of noise barriers, the swelling-type is thought to be the most suitable in diminishing the reflection noise but since a slight increase was predicted at R2, further research is necessary, based on a more sophisticated categorization of related design factors. Moreover, because swellings are difficult to produce and the size of the modules were smaller than other panels, it seems difficult to install swelling-type noise barriers. If these problems are solved, its applicable region would not be limited as other types of noise barriers. When a swelling-type noise barrier is installed at a downtown region where the amount of traffic is increasing every day, it will both secure visibility through the transparent walls and diminish any noise pollution or damages due to the reflection noise. Moreover, when decorated with more shapes and design, noise barriers will contain a visual attraction than a flat-type one and thus will alleviate any psychological impressions related to noise, other than the unique physical soundproofing functions of the soundproof panels.

The simulation results have a limitation to assess the noise on circumstance in accuracy to realism. But as a prearranged plan in large-scale installation of noise barrier, it is recommendable to pass through this process. Several researchers presented a psychological effect on personal reception of noise just by change of aesthetic condition. So with these effects, real reduction effects of designing front-shape could be a significant technology in installation of noise-countermeasures facility.

\section{Acknowledgements}

This work is supported by the Korea Institute of Civil Engineering and Building Technology, KICT, of Korean Government number 2015-0152.

\section{References}

1. Lee J, Kim E, Park T, Chang S, Kim I. Reduction Effects of Shaped Noise Barrier for Reflected Sound. Journal of Civil $\mathcal{E}$ Environmental Engineering 2015;5:171-178.

2. Chang GS, Yoon JW, Kim YC, Kim DH. The Study of the experimental evaluation for the interference device on the noise barrier edge. Proceeding of the KNSV Autumn 2001;11:844-848.

3. Lee YS, Kim YD, Kim DI, Kim JG. Study on Characteristics of Traffic Noise at Downtown Area and Diminution Methods. Seoul Health and Environment Research Institute Journal 2001;37:255-262.

4. Kim YD, Kim JY, Lee SS et al. A Study on the Frequency Characteristic and Soundproof Effect by Noise Barrier. Seoul Health and Environment Research Institute Journal 2004;40: 362-269.

5. Kim HS, Huh Y. Improvement for Maintenance Management System of Noise Barrier. The Korea Society for Noise and Vibration Engineering 2003;13:570-576. 
6. Cha SG. A Study on actual maintenance and improvement of noise barrier in Gyeongin Expressway. Proceedings of the KSNVE Annual Spring Conference 2013;4:608-610.

7. Joynt JLR, Kang J. The influence of preconceptions on perceived sound reduction by environmental noise barriers. Sci. Total Environ. 2010;408:4368-4375.

8. Hong JY, Jeon JY. The effects of audio-visual factors on perceptions of environmental noise barrier performance. Landsc. Urban Plan. 2014;125:28-37.

9. Kim DH, Joo SH. An analysis of visual preference in soundproof barriers. Journal of the Korean Institute of Landscape Architecture 2007;36:64-70.

10. Hayek SI. Mathematical modeling of absorbent highway noise barriers. Applied Acoustics 1990;31:77-100.

11. Steele C. A critical review of some traffic noise prediction models. Applied Acoustics 2001;62:271-287.

12. Garg N. and Saji S. A critical review of principal tarffic noise models: Strategies and implications. Environ. Impact Assess. Rev. 2014;46:68-81.

13. Saif MAEG, Mahmoud AA. Effectiveness of noise barriers tilted towards the traffic way over bridges. In: International Congress on Sound and Vibration; 2007 July 9-12; Cairns. p. 9-12.

14. Jonasson HG. Acoustic Source Modelling of Nordic Road Vehicles. SP Swedish National Testing and Research Institute; 2006.

15. Bendtsen H. Noise Barrier Design: Danish and Some European Examples. Danish Road Institute Report; 2010.

16. Kragh J, Plovsing B, Storeheier SA, Taraldsen G, Jonasson HG. Nordic Environmental Noise Prediction Methods. Nord2000 Summary Report: Danish Electronics Light \& Acoustics; 2002.

17. Plovsing B, Kragh J. Nord2000: Comprehensive Outdoor Sound Propagation Model. Part 1: Propagation in an Atmosphere without Significant Refraction. DELTA Acoustics \& Vibration Report AV; 2001. 